\title{
A Terapia Ocupacional e a saúde do trabalhador: panorama de produção bibliográfica
}

\author{
Fabiana Magalhães Nunes Silva, Letícia Meda Vendrúsculo-Fangel, \\ Daniela da Silva Rodrigues
}

Faculdade de Ceilândia, Universidade de Brasília - Unb, Brasília, DF, Brasil

\begin{abstract}
Resumo: Introdução: A terapia ocupacional vem apresentando uma crescente atuação na área de saúde e trabalho com intervenções na reabilitação, promoção e vigilância em saúde do trabalhador. Objetivo: O objetivo foi analisar as produções científicas da terapia ocupacional na área de saúde do trabalhador no período de 2000 a 2013 , com base no nível de evidência. Método: Realizou-se um levantamento bibliográfico das produções de artigos dos dois principais periódicos da área de terapia ocupacional no Brasil: a Revista de Terapia Ocupacional da USP e os Cadernos de Terapia Ocupacional da UFSCar, utilizando-se como descritores os termos "saúde do trabalhador", "ergonomia", "acidentes de trabalho", "trabalhador", "LER (Lesões por Esforços Repetitivos)", "reabilitação profissional” e "pessoas com deficiência". Os dados foram organizados a partir de: (a) produção por tipo de trabalho, que foram analisados de acordo com o nível de evidência; (b) produção por ano de publicações; e (c) publicação segundo objeto de estudo. Resultados: A amostra foi constituída de 30 artigos, com 90\% ( $\mathrm{n}=27)$ de nível de evidência seis; $34 \%(n=10)$ das publicações entre os anos de 2011 e 2012 e com relação à origem do primeiro autor; $90 \%(n=27)$ vinculados à instituição de ensino. Sobre o objeto de estudo, $27 \%(n=8)$ foram LER; $23 \%(n=7)$, ergonomia; $17 \%$ ( $n=5)$, saúde mental e trabalho; e 13\% (n=4), pessoas com deficiência. Conclusão: Concluiu-se que os artigos incluídos nesta pesquisa apontaram para uma predominância de abordagem de publicação. $O$ fato de não se encontrarem outros tipos de estudos revelou a necessidade de novas pesquisas com base em outras abordagens metodológicas.
\end{abstract}

Palavras-chave: Terapia Ocupacional, Saúde do Trabalhador, Ergonomia, Revisão.

\section{Occupational Therapy and workers' health: an overview of the bibliographic production}

\begin{abstract}
Introduction: Occupational therapy has presented an increasing growth in the health and occupational field, with interventions in rehabilitation, prevention, promotion and surveillance in occupational health. Objective: The study aimed to analyze occupational therapy scientific publications in the period from 2000 to 2013 , based on the level of evidence. Method: A bibliographical research on the production of papers from the two main journals in the field of occupational therapy in Brazil was developed: Revista de Terapia Ocupacional from USP and Cadernos de Terapia Ocupacional from UFSCar, using as key words, in Portuguese, corresponding to "workers' health", “ergonomics”, “work accidents”, “worker”, "RSI (Repetitive Strain Injuries)”, "professional rehabilitation”, and "people with disabilities". The data were grouped and organized as: (a) production by types of work analyzed according to the level of evidence; (b) production by years of publications; and (c) publication in accordance with the object of study. Results: The sample consisted of 30 papers, with $90 \%(n=27)$ with level of evidence six, $34 \%(n=10)$ of publications between the years 2011 to 2012 and regarding the first author affiliation, $90 \%$ ( $\mathrm{n}=27$ ) was affiliated to the educational institution. On the object of study $27 \%$ was RSI, $23 \%(n=7)$ was ergonomics, $17 \%(n=50)$ was mental health and work and $13 \%(\mathrm{n}=40)$ people with disabilities. Conclusion: It was concluded that publications included in this research point to a predominance of publishing approach. The failure to find other studies showed the need for further research based on different methodological approaches.
\end{abstract}

Keywords: Occupational Therapy, Health Workers, Ergonomics, Review.

Autor para correspondência: Daniela da Silva Rodrigues, Colegiado de Terapia Ocupacional, Universidade de Brasília, Campus Ceilândia, QNN 14, Área Especial, Ceilândia Sul, CP 7380, CEP 72220-140, Brasília, DF, Brasil, e-mail: danirodrigues.to@gmail.com

Recebido em Jan. 13, 2015; $1^{\text {a }}$ Revisão em Maio 5, 2015; 2ª Revisão em Set. 16, 2015; 3ª Revisão em Nov. 23, 2015; Aceito em Dez. 6, 2015. 


\section{Introdução}

A área da Saúde do Trabalhador (ST) é um campo de práticas e saberes interdisciplinares, que visam à integridade física, emocional e social dos trabalhadores. Atualmente, as intervençôes na área são orientadas pela Política Nacional de Saúde do Trabalhador e da Trabalhadora - PNSTT (BRASIL, 2012), cuja premissa é a atenção integral à saúde dos trabalhadores.

Na terapia ocupacional (TO), as açóes no campo da ST no Brasil, década de 1950, partiram do foco na reabilitação dos indivíduos, dentre eles os trabalhadores, o que impulsionou a criaçáo de diversos centros de recuperação, habilitação e reabilitação profissional. No entanto, o atendimento era voltado apenas para os trabalhadores contribuintes da Previdência Social, e também, não era viabilizada a reinserção para o mercado de trabalho (LAMONATO et al., 2007).

Já nos Centros de Reabilitação Profissional (CRP) do Instituto Nacional de Previdência Social (INPS), década de 1980, o modelo de atenção era desenvolvido por equipes multiprofissionais formadas por médicos, assistentes sociais, psicólogos, fisioterapeutas, terapeutas ocupacionais, enfermeiros, fonoaudiólogos, pedagogos e sociólogos. Todos os recursos terapêuticos necessários constavam do interior do próprio serviço. $\mathrm{O}$ terapeuta ocupacional atendia a clientela do serviço, os trabalhadores amputados por acidentes de trabalho que ficavam em programa de reabilitação profissional visando ao retorno ou à reinserção ao trabalho (TAKAHASHI; IGUTI, 2008).

Segundo Soares (1991), a TO vem intervir no binômio trabalho-saúde e, sob o ponto de vista da autora, assume, enquanto base fundamental, o caráter subjetivo/objetivo do trabalho como realização da capacidade humana e inserção do indivíduo na sua realidade material.

Watanabe e Nicolau (2001) revelam que os terapeutas ocupacionais brasileiros vêm desenvolvendo diversos trabalhos na área de saúde do trabalhador, exercendo diferentes papéis (funcionários da empresa, consultor, assessor, prestador de serviços, parceiro e colaborador de pesquisa e intervenção) e atuando, basicamente, em quatro frentes: reabilitação, prevenção de doenças, promoção da saúde e promoção social, mas também na investigação das atividades laborais, condiçốes, postos, organização e relaçóes do trabalho, com o objetivo de prevenir doenças ocupacionais e acidentes de trabalho.

Nos serviços públicos de saúde, como os Centros de Referência em Saúde do Trabalhador (Cerest), as ações de TO estáo articuladas com as demais ações de saúde em equipes multidisciplinares (LANCMAN; GHIRARDI, 2002), realizando atividades de assistência aos trabalhadores adoecidos ou acidentados no trabalho, traçando plano de atendimento individual ou grupal; vigilância em saúde do trabalhador, dos ambientes e condições de trabalho utilizando recursos como a ergonomia da atividade; e educação em saúde e trabalho, com açóes de capacitaçáo junto à rede para auxiliar na supervisão para notificação dos acidentados do trabalho nas unidades de urgência/emergência dos territórios municipais.

Destaca-se que a TO passa a fazer parte do cenário não apenas da saúde do trabalhador como também da Vigilância em Saúde do Trabalhador (Visat), desenvolvendo açoóes essenciais na investigação, análise e intervençáo relacionadas ao trabalho visando à promoção de saúde, bem como prevenção de agravos relacionados a acidentes e doenças ocupacionais (DALDON; LANCMAN, 2013a).

Lancman e Ghirardi (2002) afirmam a importância da atuação de terapeutas ocupacionais na área de saúde do trabalhador, por ser um profissional altamente habilitado para tratar e prevenir os agravos nutridos pelas relações homem-trabalho intimamente associadas desde os primórdios da humanidade até a contemporaneidade.

Portanto, a prática da TO no cenário da saúde do trabalhador deve incluir açóes que busquem a prevençáo de doenças ou agravos advindos de atividades laborais, reabilitação dos indivíduos já adoecidos, dando atenção especial ao homem e às questôes que permeiam a sua saúde, uma vez que as condiçóes e a forma como é organizado o trabalho constituem fatores importantes na determinação do adoecimento, permitindo, ao trabalhador, a realização de uma tomada de consciência e conhecimento acerca de sua prática, possibilitando a realização de mudanças na sua relação com o trabalho que executa (LANCMAN, 2004).

Considerando que a atuação da TO amplia-se ao inserir-se no campo da saúde do trabalhador, este trabalho buscou sintetizar e evidenciar, do ponto de vista da inserção profissional na área, produçôes científicas existentes sobre as intervençôes da TO tanto em serviços relacionados à saúde dos trabalhadores, quanto em pesquisas acadêmicas voltadas para a questão saúde e trabalho. Com isso, o objetivo foi analisar as produçôes científicas da terapia ocupacional na área de saúde do trabalhador de 2000 a 2013, com base no nível de evidência e, especificamente, buscou-se identificar os anos de publicações e o objeto de estudo que fundamentaram 
a prática baseada em evidência na área durante o período selecionado.

\section{Método}

O estudo baseia-se no método de levantamento bibliográfico da literatura, visando realizar um resgate das publicações existentes de terapia ocupacional (TO) na saúde do trabalhador (ST), compreendidas entre 2000 e 2013 . O recorte temporal da pesquisa se justifica pelas conquistas da área durante o período, como a criação da Rede Nacional de Atenção Integral à Saúde do Trabalhador (Renast) no ano de 2002, desencadeando açôes na rede de Atenção Básica, nos Centros de Referência em Saúde do Trabalhador (Cerest), o que possibilitou a entrada de terapeutas ocupacionais neste campo de atuação.

Para Lakatos e Marconi (2003), a pesquisa bibliográfica tem a finalidade de colocar o pesquisador em contato direto com o que já foi escrito, dito ou filmado sobre determinado assunto.

Foi realizada uma revisão buscando encontrar a inserção da TO no campo da saúde do trabalhador. A pesquisa pautou-se em dois periódicos de produção científica da área de terapia ocupacional no Brasil, a Revista de Terapia Ocupacional da Universidade de São Paulo (USP) e os Cadernos de Terapia Ocupacional da Universidade Federal de São Carlos (UFSCar). Como procedimento para o levantamento bibliográfico, foi realizado o acesso na própria plataforma das referidas revistas. Optou-se por ambas as revistas por apresentarem indexaçóes em bases de dados online, como a Literatura Latino-americana e do Caribe em Ciências da Saúde - Lilacs, uma das principais bases da área da saúde, que permite o acesso eletronicamente e possibilita a divulgação do conhecimento científico na área de terapia ocupacional.

Destaca-se ainda que as revistas analisadas não apresentam fator de impacto, entretanto são, atualmente, os dois principais periódicos nacionais de Terapia Ocupacional, caracterizando-se como uma importante fonte de busca de evidência científica e de divulgação da produção do conhecimento e da intervenção na área.

Os descritores utilizados foram: saúde do trabalhador, ergonomia, reabilitaçâo profissional, acidente de trabalho, LER, pessoas com deficiência, terapia ocupacional. Todos os descritores foram combinados com o termo terapia ocupacional. A Tabela 1 apresenta as combinaçôes.

Os critérios de inclusão foram publicaçôes em forma de artigo científico na língua portuguesa e que tivesse entre os autores o terapeuta ocupacional. Procedeu-se à leitura dos resumos buscando identificar dados correspondentes à inserçáo da TO na saúde do trabalhador. Quando necessário, foi realizada a leitura dos artigos na íntegra. Foram excluídas do escopo desse estudo as publicaçóes em forma de resumo de dissertaçóes ou teses, editorial, bem como os artigos que não apresentavam relação com o objeto estabelecido nesta pesquisa. Ao todo, foram encontradas 155 publicaçóes em ambas as revistas de terapia ocupacional. Destas, foi considerada uma amostra de 30 artigos que atendiam a todos os critérios de seleção.

Os dados foram organizados quantitativamente em forma de gráficos por categorias, a saber: a) produção por tipo de estudo, que foram analisadas de acordo com a força de evidência, classificada em sete níveis, conforme proposto por Melnyk e Fineout-Overholt (2005), no qual, quanto menor o número, maior será a força de evidência do estudo; b) produção por ano de publicaçóes; e c) publicação segundo objeto de estudo. A Tabela 2 apresenta os sete níveis de evidência.

\section{Resultados}

A amostra considerada neste estudo foi de 30 artigos, distribuídos entre os Cadernos de Terapia Ocupacional da Universidade Federal de São Carlos (UFSCar) e a Revista de Terapia Ocupacional da Universidade de São Paulo (USP), n=9 e n=21, respectivamente. Para melhor organização, os dados foram descritos conforme apresentados a seguir:

Tabela 1. Combinação entre os descritores e o termo terapia ocupacional.

\begin{tabular}{lll}
\hline \multicolumn{1}{c}{ Descritores } & & Termo \\
\hline Saúde do trabalhador (ST) & $e$ & Terapia Ocupacional \\
Ergonomia & $e$ & Terapia Ocupacional \\
Reabilitação Profissional (RP) & $e$ & Terapia Ocupacional \\
Acidente de Trabalho (AT) & $e$ & Terapia Ocupacional \\
LER & $e$ & Terapia Ocupacional \\
Pessoas com deficiência (PCD) & $e$ & Terapia Ocupacional \\
\hline
\end{tabular}


a) Produção por tipo de estudo e força de evidência

A partir da análise dos dados, após a leitura dos resumos, foram encontrados $93 \%(n=28)$ de artigos classificados como pesquisa e $7 \%(\mathrm{n}=2)$ de natureza teórica (Tabela 3). Os tipos de desenho de estudos entre os artigos de pesquisa foram: revisão bibliográfica, descritivo retrospectivo, descritivo exploratório, estudo de caso e relato de experiência.

Foi possível classificar a amostra das 30 publicaçóes pelo nível de evidência, de acordo com Melnyk e Fineout-Overholt (2005), apresentando uma distribuição de $90 \%$ ( $n=27)$ de força de evidência 6 (derivadas de estudo descritivo ou qualitativo); de $7 \%$ $(\mathrm{n}=2)$ de força de evidência 7 (oriundas de opiniáo); e de 3\% $(n=1)$ de força de evidência 5 (originárias de revisão sistemática de estudos descritivos e qualitativos) (Tabela 2).

Observa-se que a maioria das pesquisas incluídas neste trabalho foram delineadas como estudos qualitativos e/ou descritivos, sem a presença de nenhum ensaio clínico randomizado, acerca da intervenção da terapia ocupacional na saúde do trabalhador. Para Escosteguy (1999), os estudos randomizados são usados como padrão de referência dos métodos de pesquisa, sendo a melhor fonte de evidência científica disponível e a melhor fonte de determinação da eficácia de uma intervenção.

Tabela 2. Nível de Evidência segundo Melnyk e Fineout-Overholt (2005).

\begin{tabular}{cl}
\hline NÍVEL & \multicolumn{1}{c}{ FORÇA DE EVIDÊNCIA } \\
\hline 1 & $\begin{array}{l}\text { Evidências provenientes de Revisões Sistemáticas ou Metanálises de todos os relevantes ensaios } \\
\text { clínicos randomizados controlados ou oriundas de diretrizes clínicas baseadas em Revisões } \\
\text { Sistemáticas de ensaios clínicos randomizados controlados. }\end{array}$ \\
\hline 2 & Evidências derivadas de, pelo menos, um ensaio clínico randomizado controlado bem delineado. \\
\hline 3 & Evidências obtidas de ensaios clínicos bem delineados sem randomização. \\
\hline 4 & Evidências provenientes de estudo coorte e de caso-controle bem delineados. \\
\hline 6 & Evidências originárias de Revisão Sistemática de estudos descritivos e qualitativos. \\
\hline 7 & Evidências derivadas de um único estudo descritivo ou qualitativo. \\
\hline
\end{tabular}

Tabela 3. Produção por título, autor/ano, tipo de trabalho e identificação dos periódicos da terapia ocupacional área de saúde do trabalhador nos anos de 2000 a 2013.

\begin{tabular}{|c|c|c|c|c|}
\hline $\mathbf{N}^{\circ}$ & Título da Publicação & Autor/Ano & Tipo do estudo & $\begin{array}{l}\text { Força de } \\
\text { evidência }\end{array}$ \\
\hline \multicolumn{5}{|c|}{ Periódico: Cad. de Terapia Ocup. UFSCar } \\
\hline 1 & $\begin{array}{l}\text { Estudo de Sintomas Característicos das LER/ } \\
\text { DORT numa Universidade Pública }\end{array}$ & $\begin{array}{l}\text { Ueno e Toyoda } \\
(2002)\end{array}$ & $\begin{array}{l}\text { Descritivo, } \\
\text { exploratório }\end{array}$ & 6 \\
\hline 2 & $\begin{array}{l}\text { Intervenção Ergonômica em uma Indústria de } \\
\text { Componentes para Calçados }\end{array}$ & Silva et al. (2006) & Descritivo & 6 \\
\hline 3 & $\begin{array}{l}\text { Caracterização das pessoas com deficiência em } \\
\text { idade economicamente ativa e mapeamento das } \\
\text { instituições de assistência atuantes no munícipio } \\
\text { de São Carlos }\end{array}$ & $\begin{array}{l}\text { Rodrigues et al. } \\
\qquad(2009)\end{array}$ & Descritivo & 6 \\
\hline 4 & $\begin{array}{l}\text { Atividades de trabalho e os distúrbios } \\
\text { osteomusculares de trabalhadores em uma } \\
\text { instituição de idosos }\end{array}$ & $\begin{array}{l}\text { Montrezor e } \\
\text { Alencar (2011) }\end{array}$ & $\begin{array}{l}\text { Descritivo, } \\
\text { exploratório }\end{array}$ & 6 \\
\hline 5 & $\begin{array}{l}\text { Prevalência de Acidentes de Trabalho com Lesão } \\
\text { do Membro Superior em uma Universidade do } \\
\text { Interior o Estado de São Paulo }\end{array}$ & $\begin{array}{l}\text { Rossi, Ferrigno e } \\
\text { Cruz (2011) }\end{array}$ & $\begin{array}{l}\text { Descritivo, } \\
\text { retrospectivo }\end{array}$ & 6 \\
\hline 6 & $\begin{array}{l}\text { O Programa de Reabilitação Profissional do } \\
\text { INSS: apontamentos iniciais a partir de uma } \\
\text { experiência }\end{array}$ & $\begin{array}{l}\text { Bregalda e Lopes } \\
\qquad(2011)\end{array}$ & $\begin{array}{l}\text { Relato de } \\
\text { experiência }\end{array}$ & 6 \\
\hline 7 & $\begin{array}{l}\text { A utilização da análise ergonômica do trabalho } \\
\text { como ferramenta do terapeuta ocupacional no } \\
\text { estudo da atividade de trabalho de cabeleireiros }\end{array}$ & $\begin{array}{c}\text { Rocha e } \\
\text { Simonelli (2012) }\end{array}$ & $\begin{array}{l}\text { Estudo } \\
\text { exploratório }\end{array}$ & 6 \\
\hline 8 & $\begin{array}{l}\text { Condições de trabalho em uma cozinha industrial } \\
\text { e distúrbios osteomusculares de trabalhadores }\end{array}$ & $\begin{array}{c}\text { Alencar, } \\
\text { Cavalcanti e } \\
\text { Montezor }(2013)\end{array}$ & $\begin{array}{l}\text { Relato de } \\
\text { experiência }\end{array}$ & 6 \\
\hline 9 & $\begin{array}{l}\text { Estudo retrospectivo dos acidentes traumáticos } \\
\text { da mão relacionados ao trabalho }\end{array}$ & $\begin{array}{l}\text { Oliveira et al. } \\
\text { (2013) }\end{array}$ & $\begin{array}{l}\text { Descritivo, } \\
\text { prospectivo }\end{array}$ & 6 \\
\hline
\end{tabular}


Tabela 3. Continuação...

\begin{tabular}{|c|c|c|c|c|}
\hline $\mathbf{N}^{\circ}$ & Título da Publicação & Autor/Ano & Tipo do estudo & $\begin{array}{l}\text { Força de } \\
\text { evidência }\end{array}$ \\
\hline \multicolumn{5}{|c|}{ Periódico: Rev. de Terapia Ocup. USP } \\
\hline 10 & $\begin{array}{l}\text { A abordagem ergonômica no estudo das posturas do } \\
\text { trabalho: o caso de uma fábrica de joias }\end{array}$ & $\begin{array}{l}\text { Alves, Assunção } \\
\text { e Luz (2002) }\end{array}$ & Descritivo. & 6 \\
\hline 11 & $\begin{array}{l}\text { Pensando novas práticas em terapia ocupacional, } \\
\text { saúde e trabalho }\end{array}$ & $\begin{array}{c}\text { Lancman e } \\
\text { Ghirardi (2002) }\end{array}$ & Teórico & 7 \\
\hline 12 & $\begin{array}{l}\text { Contribuições do estudo da subjetividade na } \\
\text { análise e intervenção no trabalho }\end{array}$ & $\begin{array}{l}\text { Lancman et al. } \\
\text { (2002) }\end{array}$ & $\begin{array}{l}\text { Descritivo, } \\
\text { qualitativo }\end{array}$ & 6 \\
\hline 13 & $\begin{array}{l}\text { Informar e refletir: uma experiência de terapia } \\
\text { ocupacional na prevenção de riscos à saúde do } \\
\text { trabalhador }\end{array}$ & $\begin{array}{l}\text { Lancman et al. } \\
\qquad(2004)\end{array}$ & Descritivo & 6 \\
\hline 14 & $\begin{array}{l}\text { O impacto da organização do trabalho na saúde } \\
\text { mental: um estudo em psicodinâmica do trabalho }\end{array}$ & $\begin{array}{c}\text { Lancman e } \\
\text { Jardim (2004) }\end{array}$ & Descritivo & 6 \\
\hline 15 & $\begin{array}{l}\text { O trabalho dos agentes de trânsito do município de } \\
\text { São Paulo: uma análise ergonômica }\end{array}$ & $\begin{array}{l}\text { Gonçalves et al. } \\
(2005)\end{array}$ & Estudo de caso & 6 \\
\hline 16 & $\begin{array}{l}\text { Trabalho e deficiência: as cooperativas como } \\
\text { estratégia de inclusão social }\end{array}$ & Ghirardi (2004) & $\begin{array}{l}\text { Relato de } \\
\text { experiência }\end{array}$ & 6 \\
\hline 17 & $\begin{array}{l}\text { Método de análise de tarefas industriais como } \\
\text { ferramenta para a inclusão de portadores de } \\
\text { necessidades especiais no trabalho }\end{array}$ & $\begin{array}{c}\text { Simonelli e } \\
\text { Camarotto (2005) }\end{array}$ & Estudo de caso & 6 \\
\hline 18 & $\begin{array}{l}\text { Sofrimento psíquico e envelhecimento no } \\
\text { trabalho: um estudo com agentes de trânsito }\end{array}$ & $\begin{array}{l}\text { Lancman et al. } \\
\qquad(2006)\end{array}$ & $\begin{array}{l}\text { Descritivo, } \\
\text { exploratório } \\
\text { qualitativo }\end{array}$ & 6 \\
\hline 19 & $\begin{array}{l}\text { Aspectos relacionados ao processo de retorno } \\
\text { ao trabalho de indivíduos com desordens } \\
\text { musculoesqueléticas do membro superior: uma } \\
\text { bibliografia comentada }\end{array}$ & $\begin{array}{l}\text { Silva, Guimarães } \\
\text { e Rodrigues } \\
\quad(2007)\end{array}$ & $\begin{array}{c}\text { Revisão } \\
\text { bibliográfica } \\
\text { de estudos } \\
\text { descritivos e } \\
\text { qualitativos }\end{array}$ & 5 \\
\hline 20 & $\begin{array}{l}\text { A profissionalização de pessoas com deficiência } \\
\text { em Campinas: fragilidades e perspectivas }\end{array}$ & $\begin{array}{l}\text { Toldra e Sá } \\
\text { (2008) }\end{array}$ & Teórico & 7 \\
\hline 21 & $\begin{array}{l}\text { Distúrbios musculoesqueléticos e as atividades } \\
\text { de trabalho em uma empresa de reciclagem: um } \\
\text { enfoque em aspectos físicos }\end{array}$ & Alencar (2009) & Estudo de caso & 6 \\
\hline 22 & $\begin{array}{l}\text { Condições de trabalho e sintomas relacionados } \\
\text { à saúde de catadores de materiais recicláveis em } \\
\text { Curitiba }\end{array}$ & $\begin{array}{l}\text { Alencar et al. } \\
\quad(2009)\end{array}$ & $\begin{array}{l}\text { Descritivo, } \\
\text { exploratório }\end{array}$ & 6 \\
\hline 23 & $\begin{array}{l}\text { Aspectos da organização do trabalho e os } \\
\text { distúrbios osteomusculares: um estudo } \\
\text { com trabalhadores em instituições de longa } \\
\text { permanência de idosos }\end{array}$ & $\begin{array}{c}\text { Alencar e } \\
\text { Montrezor (2010) }\end{array}$ & $\begin{array}{l}\text { Descritivo, } \\
\text { exploratório. }\end{array}$ & 6 \\
\hline 24 & $\begin{array}{l}\text { Desafios para a inclusão no mercado de } \\
\text { trabalho de pessoas com deficiência intelectual: } \\
\text { experiências em construção }\end{array}$ & $\begin{array}{c}\text { Toldra, De } \\
\text { Marque e } \\
\text { Brunello }(2010)\end{array}$ & $\begin{array}{l}\text { Exploratório, } \\
\text { qualitativo }\end{array}$ & 6 \\
\hline 25 & $\begin{array}{l}\text { O trabalho interdisciplinar no CAPS e a } \\
\text { especificidade do trabalho do terapeuta } \\
\text { ocupacional }\end{array}$ & $\begin{array}{l}\text { Juns e Lancman } \\
\qquad(2011)\end{array}$ & $\begin{array}{l}\text { Qualitativo, } \\
\text { Descritivo }\end{array}$ & 6 \\
\hline 26 & $\begin{array}{l}\text { O afastamento do trabalho por LER/DORT: } \\
\text { repercussões na saúde mental }\end{array}$ & $\begin{array}{l}\text { Alencar e Ota } \\
\quad(2011)\end{array}$ & $\begin{array}{l}\text { Descritivo, } \\
\text { exploratório }\end{array}$ & 6 \\
\hline 27 & $\begin{array}{l}\text { Terapia ocupacional na vigilância em saúde do } \\
\text { trabalhador }\end{array}$ & $\begin{array}{c}\text { Daldon e } \\
\text { Lancman (2013a) }\end{array}$ & Descritivo & 6 \\
\hline 28 & $\begin{array}{l}\text { Relações entre condições e organização do } \\
\text { trabalho e os afastamentos de trabalhadores } \\
\text { portuários de transporte }\end{array}$ & $\begin{array}{l}\text { Alencar e Biz } \\
\quad(2013)\end{array}$ & Estudo de caso & 6 \\
\hline 29 & $\begin{array}{l}\text { O afastamento do trabalho por afecções } \\
\text { lombares: repercussões no cotidiano de vida dos } \\
\text { sujeitos }\end{array}$ & $\begin{array}{l}\text { Alencar e Terada } \\
\qquad(2012)\end{array}$ & $\begin{array}{l}\text { Descritivo, } \\
\text { exploratório }\end{array}$ & 6 \\
\hline 30 & $\begin{array}{l}\text { Organização do trabalho, conflitos e agressões } \\
\text { em uma emergência hospitalar na cidade de São } \\
\text { Paulo, Brasil }\end{array}$ & $\begin{array}{l}\text { Lancman, } \\
\text { Gonçalvez e } \\
\text { Mângia (2012) }\end{array}$ & Estudo de caso & 6 \\
\hline
\end{tabular}


Sobre a instituição de origem do primeiro autor, $90 \%(\mathrm{n}=27)$ estão vinculados à instituição de ensino, seja como docente ou discente, com destaque para Universidade de São Paulo - USP (27\%, n=8); Universidade Federal de São Paulo Unifesp (27\%, n=8); Universidade Federal de São Carlos - UFSCar (17\%, n=5); Universidade Federal de Minas Gerais - UFMG (7\%, $n=2)$; Pontifícia Universidade Católica de Campinas - PUC (7\%, n=2); Universidade Federal do Paraná - UFPR e Centro Universitário Claretiano - Ceuclar, ambas com 3\% (n=1). Apenas 10\% (n=3) dos artigos estáo relacionados aos serviços de atenção à saúde do trabalhador, como o Centro de Referência em Saúde do Trabalhador - Cerest e 3\% ( $n=1)$ do Instituto Nacional de Seguro Social (INSS).

O maior quantitativo de produçôes científicas da terapia ocupacional na área de saúde do trabalhador foi encontrado na Revista de Terapia Ocupacional da USP, o que corresponde a $70 \%$ ( $\mathrm{n}=21)$ das publicaçôes.

\section{Distribuição das publicações de 2000 a 2013}

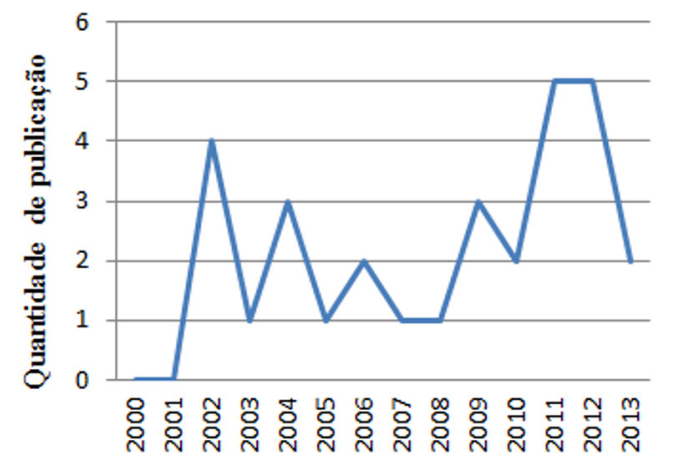

\section{Ano da publicação \\ —Podrução por ano}

Figura 1. Distribuição das publicações científicas realizadas pela terapia ocupacional área de saúde do trabalhador.

\section{Produções segundo objetos do estudo de 2000 a 2013}

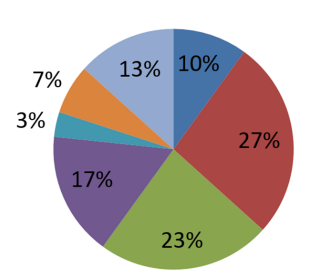

- Saúde do Trabalhador - LER

Ergonomia

- Saúde Mental e Trabalho

- Reabilitação Profissional

- Acidente de Trabalho

- Pessoas com Deficiência

Figura 2. Produções segundo objetos de estudo, no período de 2000 a 2013, realizadas pela terapia ocupacional. b) Produção por ano de publicação

Considerando o período de 2000 a 2013 de publicação dos 30 artigos, foram encontrados $n=4$ (13\%) artigos em 2002, $\mathrm{n}=1$ (3\%) artigo em 2003, $\mathrm{n}=3(10 \%)$ artigos em 2004, $\mathrm{n}=1$ (3\%) artigo em $2005, \mathrm{n}=2(7 \%)$ artigos em 2006, n=1 (3\%) artigo em 2007, n=1 (3\%) artigo em 2008, n=3 (10\%) artigos em 2009, n=2 (7\%) artigos em 2010, n=5 (17\%) artigos em 2011, n=5 (17\%) artigos em 2012 e $\mathrm{n}=2(7 \%)$ artigos em 2013. Destaca-se que nos anos 2000 e 2001 não houve nenhuma publicação, considerando ambos os periódicos, como mostra a Figura 1 a seguir.

c) Publicação segundo desenho do estudo

Em relação ao quantitativo das produçóes segundo objeto de estudo, foi possível identificar, conforme a Figura 2, que a maioria dos estudos encontrados foram sobre Lesões por Esforços, Repetitivos - LER $(\mathrm{n}=8)$ e Ergonomia ( $\mathrm{n}=7)$, seguidos de Saúde Mental e Trabalho $(n=5)$ e Pessoas com Deficiência $(n=4)$.

Apesar de estudos sobre acidente de trabalho e reabilitação profissional não estarem entre os objetos mais estudados na terapia ocupacional, $\mathrm{n}=2$ e $\mathrm{n}=1$ artigos, respectivamente, ambos representam um grande campo de intervenção da área de Saúde do Trabalhador.

\section{Discussão}

Os dados revelaram que a terapia ocupacional vem se inserindo na área de saúde do trabalhador, ao apresentar publicações significativas ao longo do período destacado. Em estudo publicado por Bezerra e Neves (2010) com o objetivo de traçar o perfil da produção científica referente à saúde do trabalhador, no período compreendido entre janeiro de 2001 e março de 2008, em que foram analisados 170 trabalhos, verificou-se que, dos 124 artigos publicados na Região Sudeste do Brasil, o Estado de São Paulo respondeu por $33,71 \%$ de toda a publicação científica.

Os achados deste estudo também apontaram um maior quantitativo de publicaçôes para a Regiáo Sudeste, 83\%. De acordo com dados do e-MEC (BRASIL, 2015), o Estado de São Paulo abriga 17 Instituições de Ensino Superior reconhecidas de graduação do curso de terapia ocupacional, bem como o maior número desses profissionais no Brasil.

Já com relação à quantidade de produçôes científicas e os seus respectivos anos de publicação, há dois momentos de pico: os anos de 2002 e 2011/2012. 
No ano de 2002, por exemplo, Lancman e Ghirardi (2002) trouxeram uma discussão sobre novas práticas da terapia ocupacional na área de saúde e trabalho. Ao relatarem sobre essas práticas, as mesmas autoras enfatizaram a participação do terapeuta ocupacional na equipe dos Centros de Referência em Saúde do Trabalhador, o que permitiu a ampliação da atuação como intervenção nos ambientes do trabalho, assistência individual e grupal aos trabalhadores, trazendo para os terapeutas ocupacionais o desafio de buscar embasamento teórico em áreas nas quais o debate estava mais avançado. Estima-se que essa discussão pode ter impulsionado as publicaçôes desse período.

Em 2005, ocorreu um momento marcante para a área, a $3^{\text {a }}$ Conferência Nacional de Saúde do Trabalhador (CNST), com o título "Trabalhar Sim!, Adoecer Não!", representando a participação dos três ministérios (Saúde, Trabalho e Emprego, Previdência Social) para discutir sobre o mundo do trabalho, seus impactos sobre a saúde e as relaçóes interinstitucionais (NOBRE, 2013). Os reflexos desse momento, de certa forma, influenciaram as pesquisas e as discussóes na área nos anos posteriores.

Em outro cenário, no ano de 2011, foi aprovada a Política Nacional de Saúde e Segurança no Trabalho - PNSST (BRASIL, 2011), buscando propor uma articulação entre os Ministérios da Saúde, Previdência e do Trabalho e Emprego. Em 2012, outro grande marco para a área de saúde de trabalhador: a publicação da Política Nacional de Saúde do Trabalhador e Trabalhadora (PNSTT).

Segundo Nobre (2013), a PNSTT aponta para uma importante revisão e reconfiguraçáo das funçôes e papéis da Rede Nacional de Atenção Integral à Saúde do Trabalhador (Renast) e dos Centros de Referências em Saúde do Trabalhador (Cerest), ao levantar a necessidade de inserção de açôes de saúde do trabalhador em todos os níveis de atenção do Sistema Único de Saúde (SUS). A Renast não está mais restrita ao centro de referência. O Cerest continua sendo fundamental e, agora, como apoio técnico especializado para toda a rede, além de assumir o apoio técnico e especializado, auxílio para as vigilâncias em saúde, presente em cada município do país.

Posteriormente, Daldon e Lancman (2013b) discutem os rumos e as incertezas da vigilância em saúde do trabalhador diante dos diferentes processos de trabalho e os mecanismos utilizados nas intervençóes no ambiente de trabalho diante da diversidade das necessidades de cada serviço voltado à ST.
Por outro lado, nos anos de 2008 e 2010, o Instituto Nacional de Seguro Social (INSS) contratou mais de 183 terapeutas ocupacionais para compor seu quadro de funcionários com base na recente proposta de revitalização da reabilitação profissional desta instituição (BREGALDA; LOPES, 2013).

Além disso, o Programa de Apoio aos Planos de Reestruturação e Expansão das Universidades Federais (Reuni) possibilitou a criação de novos cursos de Terapia Ocupacional e a composição de um corpo docente compreendendo diversas áreas de atuação deste profissional, dentre elas, a saúde do trabalhador.

Desse modo, todos os contextos acima mencionados podem ter contribuído para o desenvolvimento da produçáo de conhecimento da prática baseada em evidência da terapia ocupacional na área de saúde do trabalhador.

Nessa perspectiva, com relaçáo ao objeto de estudo, destacam-se nesta pesquisa as Lesões por Esforços Repetitivos - LER, Ergonomia e Saúde Mental e Trabalho.

Para Maeno e Wunsch Filho (2010), o aumento dessas lesôes pode ser explicado por transformaçóes do trabalho e das empresas, cuja organização tem se caracterizado pelo estabelecimento de metas e produtividade, considerando suas necessidades, particularmente de qualidade dos produtos e serviços e aumento da competitividade de mercado, sem levar em conta os trabalhadores e seus limites físicos e psicossociais.

Considerando os dados atuais da Coordenação Geral de Saúde do Trabalhador (REDE..., 2014), vinculados à Renast, sobre o número de notificação de agravos e doenças relacionadas ao trabalho no Sistema de Informaçãa de Agravos de Notificação (Sinan), as LER predominam com $74 \%$ das notificaçôes, caracterizando-se, ainda, como a doença mais prevalente no mundo do trabalho.

Já com relação aos estudos de ergonomia, os achados revelaram um direcionamento das pesquisas para análises ergonômicas do trabalho - AET (GUÉRIN et al., 2001). A Ergonomia, para a International Ergonomics Association (2015), é a disciplina relacionada ao entendimento das interaçóes entre os seres humanos e os sistemas de trabalho. Através de suas teorias, seus métodos e seus princípios, busca melhor adaptação do trabalho às características fisiológicas e psicológicas do ser humano.

Nesse sentido, a Ergonomia torna-se um recurso essencial na área de saúde do trabalhador para compreender as condiçóes e as relaçóes de trabalho, através de análises mais detalhadas das situaçóes 
ou postos de trabalho, com vistas à prevenção de doenças, ao bem-estar e à segurança do trabalhador.

Por outro lado, para Leão e Minayo Gomes (2014), existe a eminente necessidade da discussão sobre o sofrimento mental no trabalho e a importância em responder a essa demanda, que cada vez mais se torna explícita na área de vigilância em saúde do trabalhador. Nesse contexto, o estudo de Lima et al. (2014) revela a crescente demanda sobre o tema do assédio moral no trabalho, que vem sendo amplamente discutido tanto no campo acadêmico quanto na sociedade em geral.

A partir da análise das trinta publicações encontradas, constatou-se um predomínio de estudos com força de evidência 6, ou seja, estudos qualitativos descritivos, apresentando trabalhos de caracterizaçáo de uma área ou campo, possivelmente porque a saúde do trabalhador ainda é uma área recente de atuação para a terapia ocupacional. Para Gil (2002), estudos descritivos fornecem informaçôes sobre a população e sobre a compreensão de uma determinada realidade, fazem a interpretaçáo dos fatos do campo pesquisado sem interferência do pesquisador, possibilitando o conhecimento do fenômeno estudado.

Apesar das atuaçôes desse profissional nos Centros de Reabilitação do Profissional na década de 80 e, segundo Maeno e Carmo (2005), da inclusão de questôes de Saúde do Trabalhador na agenda da Reforma Sanitária Brasileira, ao apresentar um conceito mais ampliado de saúde com a criação do Sistema Único de Saúde (SUS), Constituição Federal de 1988, ainda se trata de um campo de conhecimento em construção.

Em consonância a estes dados, o estudo de Galheigo e Antunes (2008) identifica a maior parte da literatura publicada de terapia ocupacional na prática hospitalar, também por ser uma área em construção, como relatos de experiência ou pesquisas qualitativas.

Por isso, o panorama dos estudos encontrados foi de pesquisas qualitativas ou descritivas que apoiam a identificação e compreensão do cenário e desse processo de reconhecimento dentro de uma área de atuação.

\section{Conclusões}

As publicaçóes incluídas nesta pesquisa apontaram para uma predominância de nível de evidência. Fato este que demonstra a necessidade de pesquisas futuras com base em outras abordagens metodológicas, sendo essencial para a ampliação da construçấo do conhecimento e do entendimento do campo de atuação da terapia ocupacional na saúde do trabalhador.

Destaca-se, como limitação deste estudo, a revisão bibliográfica realizada apenas em revistas de terapia ocupacional, tornando-se relevantes novas pesquisas que ampliem esta revisão considerando outros periódicos da área, visto que a saúde do trabalhador é um campo interdisciplinar e com interfaces na saúde coletiva, saúde pública, epidemiologia, dentre outros.

Conclui-se que, para que a área possa se consolidar e avançar em perspectivas de conhecimento, é essencial que os terapeutas ocupacionais visem à divulgação ampliada de suas açóes vinculadas aos programas e serviços relacionados à área de saúde do trabalhador, ao ensino e à pesquisa, visto que este profissional possui um vasto campo para intervenção.

\section{Referências}

ALENCAR, M. C. B. et al. Condiçóes de trabalho e sintomas relacionados à saúde de catadores de materiais recicláveis em Curitiba. Revista de Terapia Ocupacional da Universidade de São Paulo, São Paulo, v. 20, n. 1, p. 36-42, 2009. Disponível em: <http://www.revistas.usp. br/rto/article/view/14054>. Acesso em: 18 dez. 2014.

ALENCAR, M. C. B. Distúrbios músculo-esqueléticos e as atividades de trabalho em uma empresa de reciclagem: um enfoque em aspectos físicos. Revista de Terapia Ocupacional da Universidade de São Paulo, São Paulo, v. 20, n. 2, p. 126-134, 2009. Disponível em: <http://www. revistas.usp.br/rto/article/view/14066/15884>. Acesso em: 18 dez. 2014.

ALENCAR, M. C. B.; BIZ, R. A. M. Relações entre condiçôes e organização do trabalho e os afastamentos de trabalhadores portuários de transporte. Revista de Terapia Ocupacional da Universidade de São Paulo, São Paulo, v. 23, n. 3, p. 208-215, 2013. Disponível em: $\quad<$ http://www.revistas.usp.br/rto/article/viewFile/55633/59094>. Acesso em: 18 dez. 2014.

ALENCAR, M. C. B.; CAVALCANTI, T. A.; MONTEZOR, J. B. Condiçôes de trabalho em uma cozinha industrial e distúrbios osteomusculares de trabalhadores. Cadernos de Terapia Ocupacional da UFSCar, São Carlos, v. 21, n. 1, p. 155-162, 2013. Disponível em: <http://www.cadernosdeterapiaocupacional.ufscar.br/ index.php/cadernos/article/view/741/426>. Acesso em: $18 \mathrm{dez} .2014$.

ALENCAR, M. C. B.; MONTREZOR, J. B. Aspectos da organização do trabalho e os distúrbios osteomusculares: um estudo com trabalhadores em instituiçóes de longa permanência de idosos. Revista de Terapia Ocupacional da Universidade de São Paulo, São Paulo, v. 21, n. 1, p. 15-22, 2010. Disponível em: <http://www.revistas.usp. br/rto/article/view/14081>. Acesso em: 18 dez. 2014.

ALENCAR, M. C. B.; OTA, N. H. O afastamento do trabalho por LER/DORT: repercussōes na saúde men- 
tal. Revista de Terapia Ocupacional da Universidade de São Paulo, São Paulo v. 22, n. 1, p. 60-67, 2011. Disponível em: <http://www.revistas.usp.br/rto/article/ view/14121>. Acesso em: $18 \mathrm{dez} .2014$.

ALENCAR, M. C. B.; TERADA, T. M. O afastamento do trabalho por afecçóes lombares: repercussóes no cotidiano de vida dos sujeitos. Revista de Terapia Ocupacional da Universidade de São Paulo, São Paulo, v. 23, n. 1, p. 44-51, 2012. Disponível em: <http://www.revistas.usp. $\mathrm{br} / \mathrm{rto} /$ article/viewFile/46915/50661>. Acesso em: 18 dez. 2014.

ALVES, G. B. O.; ASSUNÇÃO, A. A.; LUZ, M. G. A abordagem ergonômica no estudo das posturas do trabalho: o caso de uma fábrica de jóias. Revista de Terapia Ocupacional da Universidade de São Paulo, Sáo Paulo, v. 13, n. 3, p. 111-117, 2002. Disponível em: < http:// www.revistas.usp.br/rto/article/view/13905/15723>. Acesso em: 18 dez. 2014.

BEZERRA, M. L. S.; NEVES, E. B. Perfil da produção científica em saúde do trabalhador. Saúde e Sociedade, Sáo Paulo, v. 19, n. 2, p. 384-394, 2010. Disponível em: <http://www.revistas.usp.br/sausoc/article/viewFile/29655/31525>. Acesso em: 12 nov. 2014.

BRASIL. Decreto no 7.602, de 7 de novembro de 2011. Dispóe sobre a Política Nacional de Segurança e Saúde no Trabalho - PNSST. Diário Oficial [da] República Federativa do Brasil, Poder Executivo, DF, 7 nov. 2011. Disponível em: < http://www.planalto.gov.br/ ccivil_03/_Ato2011-2014/2011/Decreto/D7602.htm>. Acesso em: 18 dez. 2014.

BRASIL. Ministério da Saúde. Portaria nº 1.823, de 23 de agosto de 2012. Institui a Política Nacional de Saúde do Trabalhador e da Trabalhadora. Diário Oficial [da] República Federativa do Brasil, Poder Executivo, DF, 23 ago. 2012. Disponível em: <http://bvsms.saude.gov.br/ bvs/saudelegis/gm/2012/prt1823_23_08_2012.html>. Acesso em: 10 nov. 2014.

BRASIL. Ministério da Educação. Cadastro e-MEC de Instituições e Cursos de Educação Superior. Brasília, 2015. Disponível em: <emec.mec.gov.br/>. Acesso em: 10 out. 2015.

BREGALDA, M. M.; LOPES, R. E. A atuação da Terapia Ocupacional no INSS. In: SIMONELLI, A. P.; RODRIGUES, D. S. Saude e trabalho em debate: velhas questóes, novas perspectivas. Brasília: Paralelo 15, 2013. p. 293-322.

BREGALDA, M. M.; LOPES, R. E. O Programa de reabilitação profissional do INSS: apontamentos iniciais a partir de uma experiência. Cadernos de Terapia Ocupacional da UFSCar, São Carlos, v. 19, n. 2, p. 249-261, 2011. Disponível em: < http://www.cadernosdeterapiaocupacional.ufscar.br/index.php/cadernos/article/ view/466/331>. Acesso em: 18 dez. 2014.

DALDON, M. T. B.; LANCMAN, S. Terapia ocupacional na vigilância em saúde do trabalhador. Revista de Terapia Ocupacional da Universidade de São Paulo, São
Paulo, v. 23, n. 3, p. 216-222, 2013a. Disponível em: <http://www.revistas.usp.br/rto/article/view/55634>. Acesso em: 18 dez.2014.

DALDON, M. T. B.; LANCMAN, S. Vigilância em Saúde do trabalhador - rumos e incertezas. Revista Brasileira de Saúde Ocupacional, São Paulo, v. 38, n. 127, p. 92-106, 2013b. Disponível em: <http://www.scielo.br/scielo. php?pid=S0303-76572013000100012\&script=sci_arttext>. Acesso em: 11 nov. 2014.

ESCOSTEGUY, C. C. Tópicos metodológicos e estatísticos em ensaios clínicos controlados randomizados. Arquivos Brasileiros de Cardiologia, São Paulo, v. 7, n. 2, p. 1-5, 1999.

GALHEIGO, S. M.; ANTUNES, J. R. A caracterização da produção bibliográfica nas práticas hospitalares em terapia ocupacional no Brasil: uma revisão da literatura de 1990 a 2007. Revista de Terapia Ocupacional da Universidade de São Paulo, São Paulo, v. 19, n. 2, p. 91-99, 2008. Disponível em: < http://www.revistas.usp. br/rto/article/viewFile/14034/15852>. Acesso em: 12 nov. 2014

GHIRARDI, M. I. G. Trabalho e deficiência: as cooperativas como estratégia de inclusão social. Revista de Terapia Ocupacional da Universidade de São Paulo, São Paulo, v. 15, n. 2, p. 49-54, 2004. Disponível em: <http://www. revistas.usp.br/rto/article/view/13939>. Acesso em: 18 dez. 2014

GIL, A. C. Como elaborar projetos de pesquisa. São Paulo: Atlas, 2002.

GONÇALVES, R. M. A. et al. O trabalho dos agentes de trânsito do município de São Paulo: uma análise ergonômica. Revista de Terapia Ocupacional da Universidade de São Paulo, São Paulo, v. 16, n. 2, p. 82-89, 2005. Disponível em: <http://www.revistas.usp.br/rto/article/ view/13964/15782>. Acesso em: $18 \mathrm{dez} .2014$.

GUÉRIN, F. et al. Compreender o trabalho para transformá-lo: a prática da ergonomia. São Paulo: Edgard Blücher, 2001.

INTERNATIONAL ERGONOMICS ASSOCIATION - IEA. What is ergonomics? Zurich. Disponível em: <http://www.iea.cc/>. Acesso em: 10 out. 2015.

JUNS, A. G.; LANCMAN, S. O trabalho interdisciplinar no CAPS e a especificidade do trabalho do terapeuta ocupacional. Revista de Terapia Ocupacional da Universidade de São Paulo, São Paulo, v. 22, n. 1, p. 27-35, 2011. Disponível em: <http://www.revistas.usp.br/rto/article/ view/14117/15935>. Acesso em: 18 dez. 2014.

LAKATOS, E. M.; MARCONI, M. A. Fundamentos da metodologia cientifica. São Paulo: Atlas, 2003.

LAMONATO, B. C. et al. Terapia Ocupacional nas empresas. In: ENCONTRO CIENTÍFICO, 1., SIMPÓSIO DE EDUCAÇÃO UNISALESIANO, 1., 2007, Lins. Anais... Lins: Unisalesianos, 2007. p. 1-6. Disponível em: <http://www.unisalesiano.edu.br/encon- 
tro2007/trabalho/aceitos/cc33033646808.pdf>. Acesso em: 12 nov. 2014.

LANCMAN, S. et al. Contribuições do estudo da subjetividade na análise e intervenção no trabalho. Revista de Terapia Ocupacional da Universidade de São Paulo, São Paulo, v. 13, n. 1, p. 22-30, 2002. Disponível em: <http://www.revistas.usp.br/rto/article/view/13891>. Acesso em: 18 dez. 2014.

LANCMAN, S. et al. Informar e refletir: uma experiência de terapia ocupacional na prevenção de riscos à saúde do trabalhador. Revista de Terapia Ocupacional da Universidade de São Paulo, São Paulo, v. 14, n. 1, p. 1-9, 2004. Disponível em: < http://www.revistas.usp.br/rto/ article/view/13909/15727>. Acesso em: 18 dez. 2014.

LANCMAN, S. et al. Sofrimento psíquico e envelhecimento no trabalho: um estudo com agentes de trânsito. Revista de Terapia Ocupacional da Universidade de São Paulo, São Paulo, v. 17, n. 3, p. 129-136, 2006. Disponível em: <http://www.revistas.usp.br/rto/article/ view/13995>. Acesso em: 18 dez. 2014.

LANCMAN, S. Saúde, trabalho e terapia ocupacional. São Paulo: Roca, 2004.

LANCMAN, S.; GHIRARDI, M. I. G. Pensando novas práticas em terapia ocupacional, saúde e trabalho. Revista de Terapia Ocupacional da Universidade de São Paulo, São Paulo, v. 13, n. 2, p. 44-50, 2002. Disponível em: <http://www.revistas.usp.br/rto/article/view/13895>. Acesso em: 11 nov. 2014.

LANCMAN, S.; GONÇALVES, R. M. A.; MÂNGIA, E. F. Organização do trabalho, conflitos e agressóes em uma emergência hospitalar na cidade de Sáo Paulo, Brasil. Revista de Terapia Ocupacional da Universidade de São Paulo, São Paulo, v. 23, n. 3, p. 199-207, 2012. Disponível em: <http://www.revistas.usp.br/rto/issue/ view/4583>. Acesso em: 18 dez. 2014.

LANCMAN, S.; JARDIM, T. A. O impacto da organização do trabalho na saúde mental: um estudo em psicodinâmica do trabalho. Revista de Terapia Ocupacional da Universidade de São Paulo, São Paulo, v. 15, n. 2, p. 82-9, 2004. Disponível em: <http://www.revistas.usp.br/rto/ article/view/13943/15761>. Acesso em: 18 dez. 2014.

LEÂO, L. H. C.; MINAYO GOMEZ, C. A questão da saúde mental na vigilância em saúde do trabalhador. Ciência e Saúde Coletiva, Rio de Janeiro, v. 19, n. 12, p. 4649-4658, 2014. Disponível em:< http://www.scielo. br/pdf/csc/v19n12/pt_1413-8123-csc-19-12-04649. pdf $>$. Acesso em: 16 nov. 2014.

LIMA, C. Q. B. et al. Assédio moral e violências no trabalho: caracterização em perícia judicial. Relato de experiência no setor bancário. Revista Brasileira de Saúde Ocupacional, São Paulo, v. 39, n. 129, p. 101-110, 2014. Disponível em: <http://www.scielo.br/scielo. php?pid=S0303-76572014000100101\&script=sci_arttext>. Acesso em: 16 nov. 2014.
MAENO, M.; CARMO, J. C. A saúde do trabalhador no SUS. São Paulo: Hucitec, 2005.

MAENO, M.; WUNSCH FILHO, V. Reinserção no mercado de trabalho de ex-trabalhadores com LER/ DORT de uma empresa eletrônica na regiāo metropolitana de São Paulo. Revista Brasileira de Saúde Ocupacional, v. 35, n. 131, p. 53-63, 2010. Disponível em: <http://www.scielo.br/scielo.php?pid=S0303-76572010000100007\&script=sci_abstract\&tlng=pt $>$. Acesso: 18 dez. 2014

MELNYK, B. M.; FINEOUT-OVERHOLT, E. Making the case for evidence-based practice. In: MELNYK, B. M.; FINEOUT-OVERHOLT, E. Evidence-based practice in nursing \& healthcare. A guide to best practice. Philadelphia: Lippincot Williams \& Wilkins, 2005. p. 3-24.

MONTREZOR, J. B.; ALENCAR, M. C. B. Atividades de trabalho e os distúrbios osteomusculares de trabalhadores em uma instituição de idosos. Cadernos de Terapia Ocupacional da UFSCar, São Carlos, v. 19, n. 3, p. $297-$ 306, 2011. Disponível em: < http://www.cadernosdeterapiaocupacional.ufscar.br/index.php/cadernos/article/ view/500>. Acesso em: 18 dez. 2014.

NOBRE, L. C. C. A política do possível ou a política da utopia? Revista Brasileira de Saúde Ocupacional, São Paulo, v. 38, n. 128, p. 179-198, 2013. Disponível em: <http://www.scielo.br/scielo.php?pid=S0303$-76572013000200006 \&$ script $=$ sci_arttext $>$. Acesso em: 15 nov. 2014

OLIVEIRA, T. P. et al. Estudo retrospectivo dos acidentes traumáticos da mão relacionados ao trabalho. Cadernos de Terapia Ocupacional da UFSCar, São Carlos, v. 21, n. 2, p. 339-349, 2013. Disponível em: < http://www. cadernosdeterapiaocupacional.ufscar.br/index.php/cadernos/article/view/820/445>. Acesso em: 18 dez. 2014.

REDE NACIONAL DE ATENÇÃO INTEGRAL À SAÚDE DO TRABALHADOR - RENAST. Coordenação Geral da Saúde do Trabalhador. Informe de Saúde do Trabalhador: notificaçóes de agravos relacionados ao trabalho de 2007 a 2014. Brasília, 2014. Disponível em: <http://www.renastonline.org/recursos/informe-sa \%C3\%BAde-trabalhador-notifica\%C3\%A7\%C3\%B5es-agravos-relacionados-trabalho-2007-2014>. Acesso em: 18 dez. 2014.

ROCHA, L. F.; SIMONELLI, A. S. A utilização da análise ergonômica do trabalho como ferramenta do terapeuta ocupacional no estudo da atividade de trabalho de cabeleireiros. Cadernos de Terapia Ocupacional da UFSCar, São Carlos, v. 20, n. 3, p. 413-424, 2012. Disponível em: <http://www.cadernosdeterapiaocupacional. ufscar.br/index.php/cadernos/article/view/685/399>. Acesso em: 18 dez. 2014.

RODRIGUES, D. S. et al. Caracterização das pessoas com deficiência em idade economicamente ativa e mapeamento das instituiçóes de assistência atuantes no município de São Carlos. Cadernos de Terapia Ocupacional da 
UFSCar, São Carlos, v. 17, n. 2, p. 107-118, 2009. Disponível em: < http://www.cadernosdeterapiaocupacional.ufscar.br/index.php/cadernos/article/view/101/66>. Acesso em: 18 dez 2014

ROSSI, T. N.; FERRIGNO, I. S. V.; CRUZ, D. M. C. Prevalência de acidentes de trabalho com lesão do membro superior em uma universidade do interior do Estado de São Paulo. Cadernos de Terapia Ocupacional da UFSCar, São Carlos, v. 19, n. 2, p. 165-175, 2011. Disponível em: < http://www.cadernosdeterapiaocupacional. ufscar.br/index.php/cadernos/article/view/459/324>. Acesso em: $18 \mathrm{dez} 2014$.

SILVA, C. B. et al. Intervenção ergonômica em uma indústria de componentes para calçados. Cadernos de Terapia Ocupacional da UFSCar, São Carlos, v. 14, n. 1, p. 43-49, 2006. Disponível em: <http://www.cadernosdeterapiaocupacional.ufscar.br/index.php/cadernos/ article/view/166/122>. Acesso em: $18 \mathrm{dez} .2014$.

SILVA, S. R.; GUIMARÁES, E. V.; RODRIGUES, A. M. V. N. Aspectos relacionados ao processo de retorno ao trabalho de indivíduos com desordens musculoesqueléticas do membro superior: uma bibliografia comentada. Revista de Terapia Ocupacional da Universidade de São Paulo, São Paulo, v. 18, n. 1, p. 38-43, 2007. Disponível em: <http://www.revistas.usp.br/rto/article/ view/14003>. Acesso em: 18 dez. 2014.

SiMONElli, A. P.; CAMAROTTO, J. A. Método de análise de tarefas industriais como ferramenta para a inclusão de portadores de necessidades especiais no trabalho. Revista de Terapia Ocupacional da Universidade de São Paulo, São Paulo, v. 16, n. 3, p. 137-146, 2005. Disponível em: <http://www.revistas.usp.br/rto/article/ view/14027>. Acesso em: 18 dez. 2014.
SOARES, L. B. T. Terapia Ocupacional: lógica do capital ou do trabalho? São Paulo: Hucitec, 1991.

TAKAHASHI, M. A. B. C.; IGUTI, A. M. As mudanças nas práticas de reabilitação profissional da Previdência Social no Brasil: modernização ou enfraquecimento da proteção social? Cadernos de Saúde Pública, Rio de Janeiro, v. 24, n. 11, p. 2661-2670, 2008.

TOLDRÁ, R. C.; DE MARQUE, C. B.; BRUNELLO, M. I. B. Desafios para a inclusão no mercado de trabalho de pessoas com deficiência intelectual: experiências em construção. Revista de Terapia Ocupacional da Universidade de São Paulo, São Paulo, v. 21, n. 2, p. 158-165, 2010. Disponível em: <http://www.revistas.usp.br/rto/ article/view/14099/15917>. Acesso em: 18 dez. 2014.

TOLDRÁ, R. C.; SÁ, M. J. C. A profissionalização de pessoas com deficiência em Campinas: fragilidades e perspectivas. Revista de Terapia Ocupacional da Universidade de São Paulo, São Paulo, v. 19, n. 1, p. 48-55, 2008. Disponível em: <http://www.revistas.usp.br/rto/article/ view/14027>. Acesso em: 18 dez. 2014.

UENO, C. S.; TOYODA, C. Y. Estudo de sintomas característicos das Ler/Dort em uma Universidade Pública. Cadernos de Terapia Ocupacional da UFSCar, São Carlos, v. 10, n. 2, p. 94-103, 2002. Disponível em: <http:// www.cadernosdeto.ufscar.br/index.php/cadernos/article/view/211/165>. Acesso em: 18 dez. 2014.

WATANABE, M.; NICOLAU, S. M. A Terapia Ocupacional na interface da saúde e trabalho. In: DE CARLO, M. M. R. P.; BARTALOTTI, C. C. (Org.). Terapia Ocupacional no Brasil: fundamentos e perspectivas. São Paulo: Plexus, 2001. p. 155-171.

\section{Contribuição dos Autores}

Fabiana Magalhães Nunes Silva responsável pela concepção e redação do texto, organização de fontes e/ ou análises, coleta e tratamento de dados. Daniela da Silva Rodrigues colaborou no desenho do estudo, em sua análise, na revisão crítica do artigo e na orientação do trabalho. Letícia Meda Vendrúsculo-Fangel colaborou na revisão crítica do artigo. Todos os autores aprovaram a versão final do texto. 